\title{
Determination of Aflatoxins in Medicinal Plants by High-Performance Liquid Chromatography-Tandem Mass Spectrometry
}

\author{
Nadeem A. Siddique ${ }^{\mathrm{a}}$, Mohd Mujeeb ${ }^{\mathrm{a}}$, Sayeed Ahmad ${ }^{\mathrm{a}}$, Bibhu P. Panda ${ }^{\mathrm{b}}$, Mohd Makhmoor ${ }^{\mathrm{b}}$ \\ ${ }^{a}$ Department of Pharmacognosy and Phytochemistry, Faculty of Pharmacy, Jamia Hamdard (Hamdard University), New \\ Delhi-110062, India. ${ }^{\mathrm{b}}$ Microbial and Pharmaceutical Biotechnology Laboratory, Faculty of Pharmacy, Jamia Hamdard \\ (Hamdard University), New Delhi, India.
}

Received, June 1, 2013; Revised; Accepted, July 11, 2013; Published, July 14, 2013.

\begin{abstract}
Purpose. The intention of the proposed work is to study the presence of the aflatoxins $\mathrm{B}_{1}, \mathrm{~B}_{2}, \mathrm{G}_{1}$ and $\mathrm{G}_{2}$ in medicinal plants, namely Mucuna pruriens, Delphinium denudatum and Portulaca oleraceae. Methodology. The aflatoxins were extracted, purified by immunoaffinity column chromatography and analysed by high-performance liquid chromatography-tandem quadrupole mass spectrometry with electrospray ionisation (HPLC-MS/MS). Fungal count was carried out in PDA media. Results. A good linear relationship was found for $\mathrm{AFB}_{1}, \mathrm{AFB}_{2}, \mathrm{AFG}_{1}$ and $\mathrm{AFG}_{2}$ at 1-10 ppb ( $\left.\mathrm{r}>0.9995\right)$. The analyte accuracy under three different spiking levels was $86.7-108.1 \%$, with low per cent relative standard deviations in each case. The aflatoxins can be separated within 5 to 7 min using an Agilent XDB C18-column. We found that $\mathrm{AFB}_{1}$ and $\mathrm{AFB}_{2}$ were in trace amounts below the detection limit in M. pruriens whilst they were not detected in D. denudatum. P. oleraceae was found to be contaminated with $\mathrm{AFB}_{1}$ and $\mathrm{AFB}_{2}$. $\mathrm{AFG}_{1}$ and $\mathrm{AFG}_{2}$ were not detected in M. pruriens, $P$. oleraceae and were below the detection limit in $D$. denudatum. This was consistent with very low numbers of fungal colonies observed after $6 \mathrm{hr}$ of incubation. Conclusion. The analytical method developed is simple, precise, accurate, economical and can be effectively used to determine the aflatoxins in medicinal plants and therefore to control the quality of products. The aflatoxin levels in the plant extracts examined were related to the minimal fungal load in the medicinal plants examined.
\end{abstract}

This article is open to POST-PUBLICATION REVIEW. Registered readers (see "For Readers") may comment by clicking on ABSTRACT on the issue's contents page.

\section{INTRODUCTION}

The plants Mucuna pruriens, Delphinium denudatum and Portulaca oleraceae have the potential for wide therapeutic applications. Mucuna pruriens L (Velvet beans; Fabaceae), a herbaceous forage and food legume, has found widespread usage in the management of several diseases, including diabetes, rheumatoid arthritis, atherosclerosis, male infertility and nervous disorders, and is a good source of 3,4- dihydroxyphenylalanine (DOPA) (1, 2 ). In addition to health benefits the seeds possess potent aphrodisiac, geriatric tonic and vermifuge activities (3). The major constituent of Mucuna seeds was found to be L-dopa (5\%), along with minor amounts of methylated and nonmethylated tetrahydroisoquinolines $(0.25 \%)$ (4). Delphinium denudatum Wall (Jadwar; Ranunculaceae) is one of the important medicinal drugs used as indigenous medicine in India, and the entire plant is reported to be useful in a variety of ailments (5). The root is used in various medical formulations in Unani and Ayurveda to reduce the withdrawal symptoms in people on de-addiction therapy (6). It is a natural analgesic and is prescribed for relief from toothache (7). Herbalists recommend the roots in the treatment of fungal infections, asthma, cough, jaundice and nervous problems (8). It is considered as a natural blood purifier and prescribed for people who have digestive problems and provides relief from painful wounds and inflammation (9). Chemically $D$. denudatum contains many active compounds, some of which are alkaloids including delphocurarine, staphisagrine, delphine, condelphine, denudatin, talatizidine, acetylhetero-phylistine and a

\footnotetext{
Corresponding Author: Mohd Mujeeb, M.Pharm, Ph.D; Assistant Professor; Bio Active Natural Product Laboratory (Nano Building); Department of Pharmacognosy and Phytochemistry; Faculty of Pharmacy; Jamia Hamdard (Hamdard University); New Delhi, India; E-mail: mhdmjb@gmail.com
} 
diterpenoid alkaloid identical to condelphine (10). Portulaca oleracea L. (Purslane; Portulaceae) grows widely in different areas of the world including India. The seeds are regarded as valuable in the treatment of urinary problems, digestive problems and cardiovascular diseases (11). Studies demonstrated a variety of pharmacological activities, including hypoglycemic (12, 13), hypocholesterolemic, antioxidant, analgesic, antiinflammatory, skeletal muscle relaxant, smooth muscle relaxant, neuroprotective (14), anxiolytic, sedative, anticonvulsant, antiulcerogenic, bronchodilatory, wound healing, and antifungal effects (15). It contains a variety of bioconstituents, including catecholamines, 1-noradrenaline, dopamine, $\alpha$-amyrin, $\beta$-amyrin and portuloside $\mathrm{A}$ $(16,17,18)$.

Aflatoxins are a group of structurally related toxic metabolites of mycotoxins produced by Aspergillus flavus and Aspergillus parasticus (19). In the aflatoxin group, about 16 compounds are known, but only aflatoxin $\mathrm{B}_{1}, \mathrm{~B}_{2}, \mathrm{G}_{1}, \mathrm{G}_{2}, \mathrm{M}_{1}$ and $\mathrm{M}_{2}$ are routinely monitored $(20,21)$. Aflatoxin $\mathrm{B}_{1}, \mathrm{~B}_{2}$, $\mathrm{G}_{1}$ and $\mathrm{G}_{2}$ are chemical derivatives of difurancoumarin (Fig. 1). Aflatoxin $\mathrm{B}_{1}$ is the prevalent compound in plant samples and it is acutely toxic and the most carcinogenic amongst the aflatoxins (22). Aflatoxins may increase stress

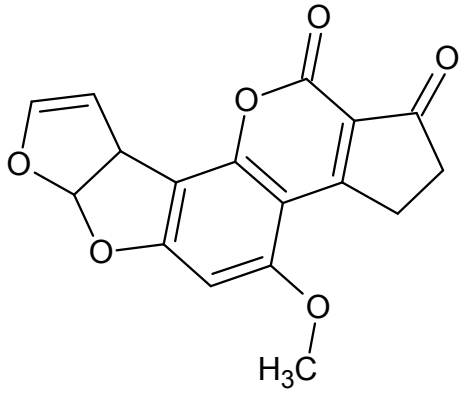

a

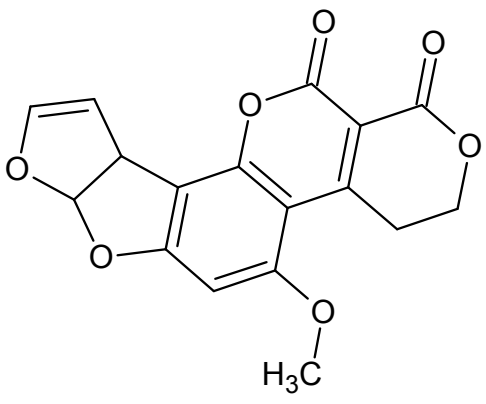

c susceptibility and compromise growth efficiency. The clinical signs of aflatoxicosis in humans are extremely varied. Signs of acute aflatoxicosis include depression, nervousness, abdominal pain, diarrhea and death (23). The aflatoxins occur widely in food, especially in corn, nuts, peanuts, coconut, fruits, dried fruits and beer $(24,25)$. High moisture and temperature are two main factors that cause the occurrence of mycotoxins at pre-harvest and post harvest stages (26). Fungi are widely distributed as environmental contaminants (27), in fact, under favorable conditions of temperature and humidity, they grow on many commodities including cereals, oil seeds, nuts, herb-teas and spices (28). They have also been found in medicinal herbs that are not fully dried or stored improperly (e.g. at high temperature and humidity) $(29,30)$. Despite many studies on mycotoxins in agricultural products, only a few are concerned with spices and herbal medicines. The determination of aflatoxins in herbs is becoming important for medicinal safety, as more and more people are using medicinal herbs for complementary and alternative therapy and they play an important role in the economy, especially in developing countries. Previously aflatoxins were analyzed in peanut, cocoa, pistachio, chili, ginger $(31,32)$, chocolate, cotton-seed, job's tears, pepper, paprika, feed and wheat samples (33).<smiles>COc1cc2c(c3oc(=O)c4c(c13)CCC4=O)C1(O)CCOC1O2</smiles><smiles>COc1cc2c(c3oc(=O)c4c(c13)CCOC4=O)C1CCOC1O2</smiles>

d

Figure 1. Structure of (a) $A F B_{1}$ (b) $A_{F B}$ (c) $A_{F F}$ (d) $A F G_{2}$ 
The current acceptance level of total aflatoxin in maize set by the United States- Food and Drug Administration (USFDA) is $20 \mu \mathrm{g} / \mathrm{kg}$ (34). Health Canada has set acceptance criteria of $<20 \mu \mathrm{g} / \mathrm{kg}$ (ppb) for aflatoxins $\left(\mathrm{B}_{1}+\mathrm{B}_{2}+\mathrm{G}_{1}+\mathrm{G}_{2}\right)$, and $<5 \mu \mathrm{g} / \mathrm{kg}$ $(\mathrm{ppb})$ for aflatoxin $\mathrm{B}_{1}$ for evening primrose oil, sugar cane, sugar beets, cottonseed, peanuts, corn, ginseng or any substance derived from these sources (35). Recently, the Codex Alimentarius Commission, the Joint FAO/WHO Food Standards Program, adopted a limit of $15 \mu \mathrm{g} / \mathrm{kg}$ for total aflatoxins (36). In 2008, the Codex Alimentarius set a maximum level of 10 $\mu \mathrm{g} / \mathrm{kg}$ total aflatoxins in ready-to-eat almonds, hazelnuts, and pistachios (37). In the European Union, the total aflatoxins and $\mathrm{AFB}_{1}$ levels in human commodities are regulated with maximum residue levels (MRLs) that cannot be greater than 2 and 4 $\mu \mathrm{g} / \mathrm{kg}$, respectively (38). In the year 2002 the European Food Safety Authority (EFSA) set maximum limits in spices (Capsicum spp., Piper spp., Myristicafragrans, Zingiber officinale, Curcuma longa) (AFB $5 \mu \mathrm{g} / \mathrm{kg}$; total AFs $10 \mu \mathrm{g} / \mathrm{kg}$ ) (02/472/EC) (39).

Environmentally sound and most widespread methods applicable for quantitative determination of aflatoxin content in different samples are thin-layer chromatography $(40,41)$ and high performance liquid chromatographic (HPLC) $(42,43)$. Aflatoxins can be separated and detected using either normal- or reversed-phase HPLC methods mainly with fluorescence spectrometric detection. The use of two-dimensional thin-layer chromatography (2DTLC) $(44,45)$ and high performance thin-layer chromatography (HPTLC) for the determination of aflatoxins has been reported (46). An alternative complex media based method is reported to detect the natural fluorescence of aflatoxins released by the growing mycelium (47) or relies on multiplex polymerase chain reaction (PCR) and real time polymerase chain reaction (RT-PCR) detection of genes or their transcripts involved in the aflatoxin biosynthetic pathway $(48,49)$. An enzyme-linked immunosorbent assay (ELISA) for $\mathrm{AFB}_{1}$, and levels of total aflatoxins were quantified and confirmed by liquid chromatography combined with tandem mass spectrometry (LC-MS/MS) (50). However, a lot of time and a tedious pre-or post-column derivatization is required with conventional HPLC in order to provide better detection limits of $\mathrm{AFB}_{1}, \mathrm{AFB}_{2}, \mathrm{AFG}_{1}$ and $\mathrm{AFG}_{2}(51)$. Furthermore, many other structurally similar components to the AFs in the plants can also be retained by the aflatoxin immunoaffinity column, and as a result produce false positive results in many chromatographic techniques.

Despite the numerous uses and the various biologically active chemical constituents reported in $M$. pruriens, $D$. denudatum and $P$. oleracea, no data on aflatoxin detection of these plants are available in the literature. In order to ensure safety and quality we have collectively developed a cost efficient, flexible and rapid method for the quantification of aflatoxins in $M$. pruriens, $D$. denudatum and $P$. oleraceae as these plants are commonly consumed by people without any awareness of their safety. There exist no well-accepted scientific methods for proper determination and quality control of aflatoxins in selected plant materials. The aim of this study was to screen the content of aflatoxins as well as providing a sensitive, accurate and reproducible analytical method for the detection of aflatoxins. Further, the purpose of this study is to provide useful information on aflatoxin levels in $M$. pruriens, $D$. denudatum and $P$. oleraceae and to achieve a confirmatory method for quick determination of $\mathrm{AFB}_{1}, \mathrm{AFB}_{2}, \mathrm{AFG}_{1}$ and $\mathrm{AFG}_{2}$ by high performance liquid chromatographyelectrospray ionization tandem mass spectrometry (HPLC-MS/MS). The proposed method overcame the drawbacks of HPLC by using tandem MS/MS detection, which can determine the presence of a specific substance more accurately than HPLC and avoids the tedious derivatization process. The method is validated for linearity, recovery, sensitivity, precision and repeatability, and was shown to successfully determine the levels of AFs in plants samples.

\section{METHODS}

\section{Equipment and chemicals}

The analysis was performed on an Agilent 1200 system using an Agilent XDB-C18 4.6-50 mm column containing $1.8 \mathrm{~mm}$ particles. MS/MS detection was achieved on an Agilent 6410B tandem quadrupole mass spectrometer using an electrospray ion (ESI) source in positive mode. Data were acquired and processed using the Masshunter software (Agilent). Acetonitrile, methanol, ammonium acetate and HPLC grade water were supplied by Merck (Darmstadt, Germany). $\mathrm{AFB}_{1}$, $\mathrm{AFB}_{2}, \mathrm{AFG}_{1}$ and $\mathrm{AFG}_{2}$ were purchased from Sigma (St. Louis, MO). All other inorganic chemicals and organic solvents were of reagent grade. 


\section{HPLC-MS/MS analysis}

Chromatographic analyses were carried out using a binary gradient elution with $70: 30 \mathrm{v} / \mathrm{v}$ methanol: acetonitrile as eluent $\mathrm{A}$ and $5 \mathrm{mM}$ aqueous ammonium acetate as eluent $\mathrm{B}$. The total run time was 5 to $8 \mathrm{~min}$. The injection volume was $5 \mathrm{~mL}$, the flow rate was set at $5 \mu \mathrm{L} / \mathrm{min}$ and the column temperature was maintained at $30^{\circ} \mathrm{C}$. The ionisation source of the MS/MS detector had $4.0 \mathrm{kV}$ capillary voltage, $350{ }^{\circ} \mathrm{C}$ source temperature and $9 \mathrm{~L} / \mathrm{min}$ desolvation gas flow (both gases were nitrogen).

\section{Sample collection}

All sample species were collected from a local market of New Delhi, India and were authenticated by Dr. H.B. Singh (Chief Scientist \& Head, Raw materials Herbarium \& Museum, NISCAIR, New Delhi). A voucher specimen (RHMD/1704/04) has been deposited in the Department of Pharmacognosy and Phytochemistry, Faculty of Pharmacy, Jamia Hamdard, New Delhi. All samples were ground to powders and kept in moisture proof paper bags to keep their water content constant before analysis. The herbs and their parts used are summarized in Table 1.

\section{Sample preparation}

The samples $(5 \mathrm{~g})$ were sonicated in $100 \mathrm{~mL}$ 70:30 $\mathrm{v} / \mathrm{v}$ methanol:water for $45 \mathrm{~min}$ and centrifuged (Remi Compufuge-CR30) for $10 \mathrm{~min}$, then $5 \mathrm{~mL}$ of the supernatant was drawn, diluted with $30 \mathrm{~mL}$ milli$\mathrm{Q}$ water, and passed through the immunoaffinity column at no more than $5 \mathrm{~mL} / \mathrm{min}$ (the column was previously conditioned with $30 \mathrm{~mL}$ distilled water). The column was rinsed with $15 \mathrm{~mL}$ double distilled water to remove the matrix components and then dried by passing air through to remove any adherent water. The eluate was diluted to $2 \mathrm{~mL}$ with water and passed through a $0.22 \mathrm{~mm}$ filter, and the filtrate was injected into the HPLC-MS/MS.

\section{Peak recognition}

The AFs in samples were recognized by comparing their retention times and MS spectra (MRM mode) with the standards. The standards used are summarized in Table 1.

\section{Fungal count in the plant materials}

All the plant materials were diluted with sterile water and $500 \mu \mathrm{L}$ of the samples were spread over potato dextrose agar (PDA)-Ox bile media. They were incubated for 5 days at $28{ }^{\circ} \mathrm{C}$ and $75 \%$ relative humidity, and the colony forming units (CFU) of the fungal strains were observed.

\section{RESULTS}

\section{Selection of mobile phase}

The HPLC mobile phase was optimized by considering the retention time, peak response, sensitivity, peak sharpness as well broadening and separation efficiencies. Methanol-water in the combination of $60: 40 \mathrm{v} / \mathrm{v}$ completely separated the analytes but was found not suitable for the column, while acetonitrile-water $60: 30 \mathrm{v} / \mathrm{v}$ failed to separate the AFs. Methanol:acetonitrile in a combination of $70: 30 \mathrm{v} / \mathrm{v}$ with $5.0 \mathrm{mM}$ aqueous ammonium acetate was found the best mobile phase for AF standards separation (Fig. 2).

\section{Optimisation of the mass spectra}

Mass spectrometry detection was carried out on positive ionisation mode because this mode gave sharp and sensitive signals. Mass spectrometry detection was optimised by injecting the $\mathrm{AF}$ standards $(100 \mathrm{ng} / \mathrm{mL})$ under positive ionisation mode. The ion fragments were evaluated by their run time to the most abundant $\mathrm{m} / \mathrm{z}$ and the ion with the uppermost intensity was selected as the basic ion for quantitation (Fig. 3).

\begin{tabular}{llll}
\hline \multicolumn{3}{l}{ Table 1. Summary of aflatoxins and herbs used in this study } \\
\hline \multicolumn{2}{c}{ Standard aflatoxin } & Tested herb & Family \\
\hline $\mathrm{B}_{1}$ & Part used & Species & \\
$\mathrm{B}_{2}$ & Seed & Mucuna pruriens & Fabaceae \\
$\mathrm{G}_{1}$ & Root & Delphinium denudatum & Ranunculaceae \\
$\mathrm{G}_{2}$ & Seed & Portulaca oleraceae & Portulacaceae \\
\hline
\end{tabular}




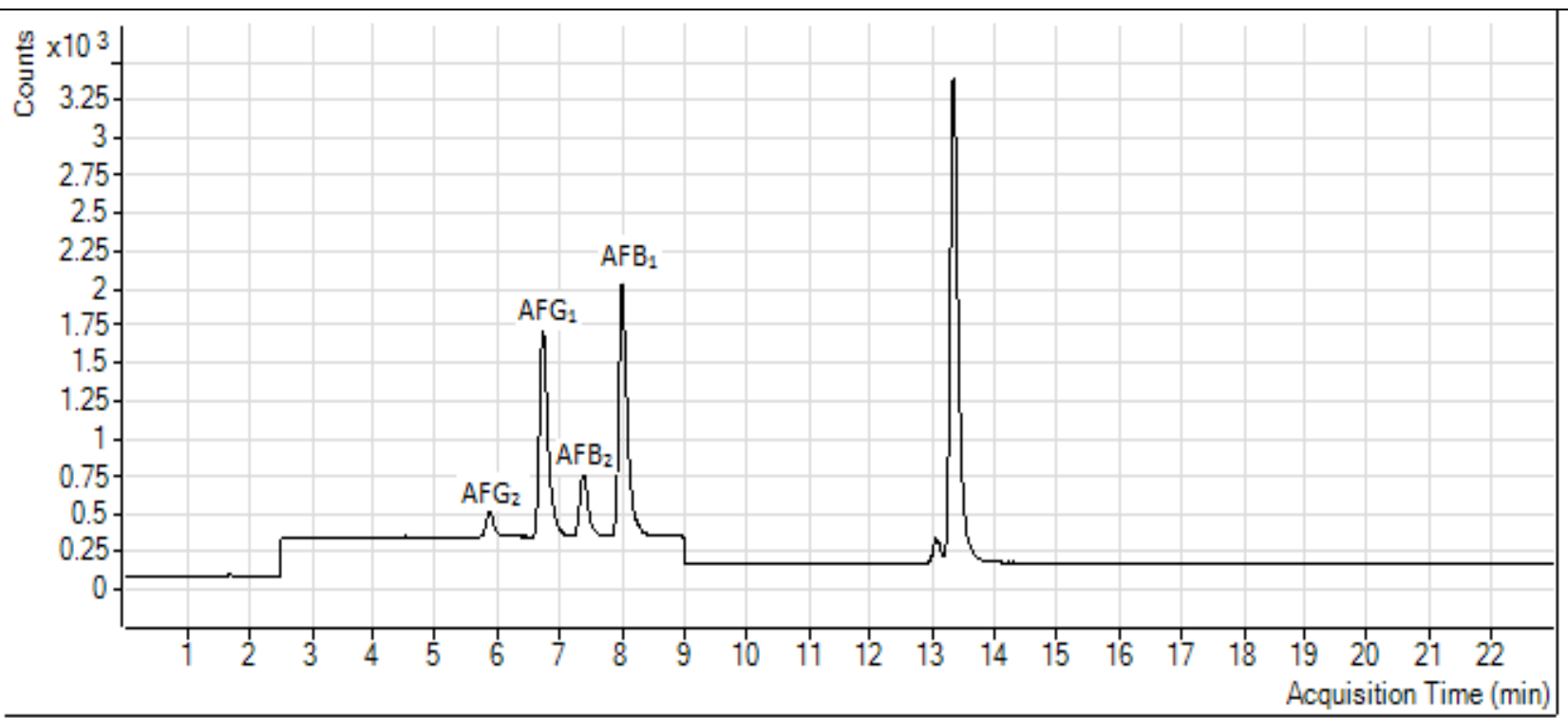

Figure 2. HPLC-MS/MS Chromatograms of standard mycotoxins comprising a mixture of aflatoxins $\left(B_{1}, B_{2}, G_{1}\right.$ and $\left.G_{2}\right)$. Mobile phase; methanol: acetonitrile $(70: 30 \mathrm{v} / \mathrm{v})$ eluent $\mathrm{A}$ and aqueous ammonium acetate $(5 \mathrm{mM})$ eluent $\mathrm{B}$. Total run time $(5$ to $8 \mathrm{~min})$, injection volume $(5 \mathrm{~mL})$ and flow rate $(5 \mu \mathrm{L} / \mathrm{min})$.
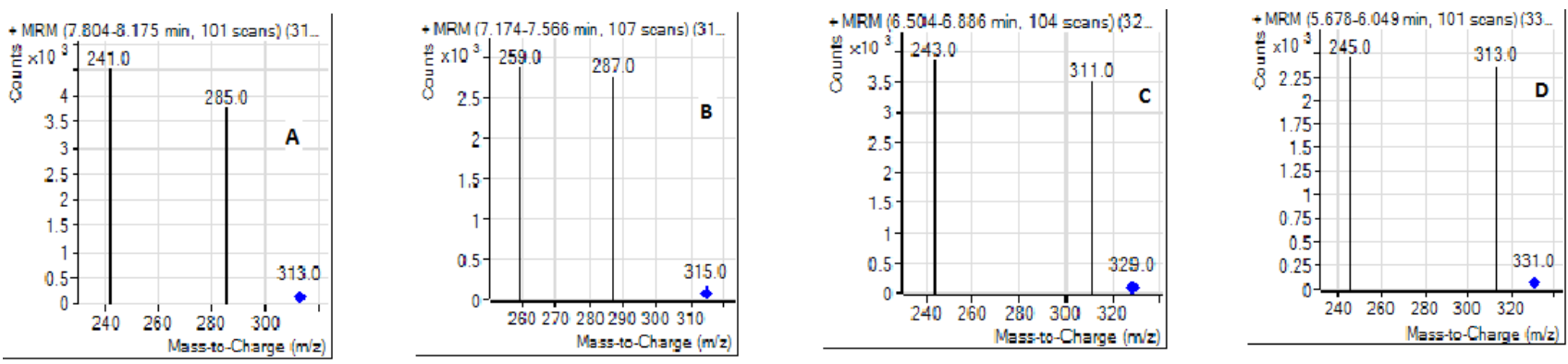

Figure 3. Mass spectral analysis of standard aflatoxins. (A) Std. AFB 1 run time (7.8-8.1) and $\mathrm{m} / \mathrm{z}(313.0)[\mathrm{M}+\mathrm{H}]^{+}$(B) $\mathrm{AFB}_{2}$ run time (7.1-7.5) and $\mathrm{m} / \mathrm{z}(315.0)[\mathrm{M}+\mathrm{H}]^{+}(\mathrm{C}) \mathrm{AFG}_{1}$ run time (6.5-6.8) and $\mathrm{m} / \mathrm{z}(329.0)[\mathrm{M}+\mathrm{H}]^{+}$(D) $\mathrm{AFG}_{2}$ run time (5.6$6.0)$ and $\mathrm{m} / \mathrm{z}(331.0)$.

\section{METHOD VALIDATION}

\section{Limits of detection and limits of quantification}

The AF analyses showed good results in the MRM mode, the LOD reaching $0.28-1.10 \mu \mathrm{g} / \mathrm{kg}$ and LOQ $0.79-3.34 \mu \mathrm{g} / \mathrm{kg}$, with a signal-to-noise ratio (S:N) of 3 . Linear calibration curve for various concentrations of AFs ranging from $1 \mathrm{ppb}-10 \mathrm{ppb}$ (three points) were analysed. The calibration curves were constructed by plotting the response against the concentration. A linear relationship was obtained for each compound, and the correlation coefficients ranged from 0.9992 to 0.9995 (Table 2). The relative standard deviations (RSDs) of precision of AF mixtures were 7.04-2.17\% $(n=6)$. Excellent retention times for $\mathrm{AFB}_{1}$
(7.973 \pm 0.018$), \quad \mathrm{AFB}_{2} \quad(7.361 \pm 0.017), \quad \mathrm{AFG}_{1}$ $(6.689 \pm 0.015)$ and $\mathrm{AFG}_{2} \quad(5.830 \pm 0.026)$ were observed for corresponding mixtures of AFs (Table 2).

\section{Accuracy}

Accuracy analysis was performed by testing samples at three different concentrations $1 \mathrm{ppb}, 5 \mathrm{ppb}$ and 10 ppb. All plants were used for the accuracy test to ensure that the method has wide adaptability. The plant sample (5 g) was spiked with high, medium and low levels of AF standards. The accuracy ranged from $86.7 \%$ to $108.1 \%$ (Table 3), indicating good accuracy of the method. 
Determination of aflatoxins in plant samples

HPLC-MS/MS Chromatograms (Counts vs

Acquisition time (min)) for $\mathrm{AFB}_{1}, \mathrm{AFB}_{2}, \mathrm{AFG}_{1}$ and $\mathrm{AFG}_{2}$ were determined for M. pururiens (Fig. 4), D. denudatum (Fig. 5) and P. oleraceae (Fig. 6). The study revealed mass peaks of $\mathrm{AFB}_{1}$ and $\mathrm{AFB}_{2}$ in $M$. pruriens below the detection limit whilst a resultant mass peak of $\mathrm{AFB}_{1}$ and $\mathrm{AFB}_{2}$ was observed in $P$. oleraceae, whereas no mass peak was found in $D$. denudatum (Figs. 4, 5 and 6). The aflatoxin levels in the plants investigated is summarized in Table 4.

\section{Fungal count}

Total fungal colonies observed per gram of $M$. pruriens, $D$. denudatum and $P$. oleraceae were $18 \times 10^{2}, 4 \times 10^{2}$ and $20 \times 10^{2}$ respectively in PDA-ox bile media. The total fungal CFU also show that there was very low growth of fungus in these tested plant materials, which is consistent with the low levels of mycotoxins.

\section{DISCUSSION}

An LC-MS method was developed which was found to be suitable for the rapid and accurate assessment of aflatoxin levels in selected plant samples. The method was subsequently applied to determine the natural occurrence of AFs in selected widely used commercial medicinal plant samples (Table 1). We found that $P$. oleraceae was contaminated with $\mathrm{AFB}_{1}$ $(1.675 \mu \mathrm{g} / \mathrm{kg})$ and $\mathrm{AFB}_{2}(1.335 \mu \mathrm{g} / \mathrm{kg})$, whilst levels in $M$. pruriens were below the detection limit for $\mathrm{AFB}_{1}(0.04 \mu \mathrm{g} / \mathrm{kg})$ and $\mathrm{AFB}_{2}(0.05 \mu \mathrm{g} / \mathrm{kg})$ and were not detected in D. denudatum. $\mathrm{AFG}_{1}$ and $\mathrm{AFG}_{2}$ were absent in $M$. pruriens and $P$. oleraceae, whilst a relatively low value $(0.07 \mu \mathrm{g} / \mathrm{kg})$ of $\mathrm{AFG}_{2}$ was found in D. denudatum (Table 4).

Table 2. Linearity, limit of detection, limit of quantification and precision for the analysis of $\mathrm{AFB}_{1}, \mathrm{AFB}_{2}, \mathrm{AFG}_{1}$ and $\mathrm{AFG}$ : by HPLC-MS/MS. Data expressed as mean $\pm \mathrm{SD}$. ${ }^{\mathrm{a}} \mathrm{n}=6 ;{ }^{\mathrm{b}}$, bl $\mathrm{S} / \mathrm{N}=3$ (Signal-to-noise ratio); ${ }^{\mathrm{c}} \mathrm{n}=6$. Abbreviations: RT: Retentior Time; LOD: Limit of detection; LOQ: Limit of quantification; RSD: Relative standard deviations.

\begin{tabular}{|c|c|c|c|c|c|c|c|}
\hline \multirow[t]{3}{*}{ Compound } & \multirow[t]{2}{*}{$\mathrm{RT} \pm \mathrm{SD}$} & \multirow{2}{*}{$\begin{array}{l}\text { Regression } \\
\text { Slope }\end{array}$} & \multirow{2}{*}{$\begin{array}{l}\text { Correlation } \\
\text { Intercept }\end{array}$} & \multirow{2}{*}{$\begin{array}{l}(\mathrm{LOD})_{\mathrm{b}} \\
\text { Coefficient }_{\mathrm{a}}\end{array}$} & \multirow{2}{*}{$\begin{array}{l}(\mathrm{LOQ})_{\mathrm{b}}{ }^{1} \\
\mu \mathrm{g} / \mathrm{kg}\end{array}$} & \multicolumn{2}{|c|}{ Precision $_{\mathrm{c}}$} \\
\hline & & & & & & $\mu \mathrm{g} / \mathrm{kg}$ & (RSD \%) \\
\hline & & & & $\mathrm{R}^{2}$ & & & \\
\hline $\mathrm{B}_{1}$ & $7.973 \pm 0.018$ & -44.8238 & 927.2519 & 0.9992 & 0.2849 & 0.7996 & 0.704988 \\
\hline $\mathrm{B}_{2}$ & $7.361 \pm 0.017$ & -11.4898 & 742.1691 & 0.9995 & 0.6903 & 2.0918 & 0.155408 \\
\hline $\mathrm{G}_{1}$ & $6.689 \pm 0.015$ & -180.806 & 787.3258 & 0.9859 & 0.0839 & 0.2545 & 0.048938 \\
\hline $\mathrm{G}_{2}$ & $5.830 \pm 0.026$ & -12.9685 & 277.9480 & 0.9991 & 1.1044 & 3.3468 & 0.217735 \\
\hline
\end{tabular}

\begin{tabular}{|c|c|c|c|}
\hline Compound & Concentration (ppb) & Response $^{\mathrm{a}} \pm \mathrm{SD}$ & Accuracy (\%) \\
\hline $\mathrm{AFB}_{1}$ & $\mathrm{~L}$ & $955.66 \pm 5.13$ & 108.1 \\
\hline $\mathrm{AFB}_{2}$ & $\mathrm{~L}$ & $224.33 \pm 4.50$ & 105.8 \\
\hline $\mathrm{AFG}_{1}$ & $\mathrm{~L}$ & $665 \pm 4.0$ & 107.4 \\
\hline $\mathrm{AFG}_{2}$ & $\mathrm{~L}$ & $77 \pm 2.64$ & 108.7 \\
\hline $\mathrm{AFB}_{1}$ & $\mathrm{M}$ & $4456.66 \pm 5.508$ & 97.1 \\
\hline $\mathrm{AFB}_{2}$ & $\mathrm{M}$ & $1074.66 \pm 3.512$ & 97.9 \\
\hline $\mathrm{AFG}_{1}$ & $\mathrm{M}$ & $3232.33 \pm 4.163$ & 86.7 \\
\hline $\mathrm{AFG}_{2}$ & $\mathrm{M}$ & $391.66 \pm 3.055$ & 96.9 \\
\hline $\mathrm{AFB}_{1}$ & $\mathrm{H}$ & $9286.66 \pm 5.132$ & 100.6 \\
\hline $\mathrm{AFB}_{2}$ & $\mathrm{H}$ & $2224.66 \pm 4.509$ & 100.5 \\
\hline $\mathrm{AFG}_{1}$ & $\mathrm{H}$ & $8158.33 \pm 5.033$ & 105.9 \\
\hline $\mathrm{AFG}_{2}$ & $\mathrm{H}$ & $826.66 \pm 4.509$ & 100.7 \\
\hline
\end{tabular}



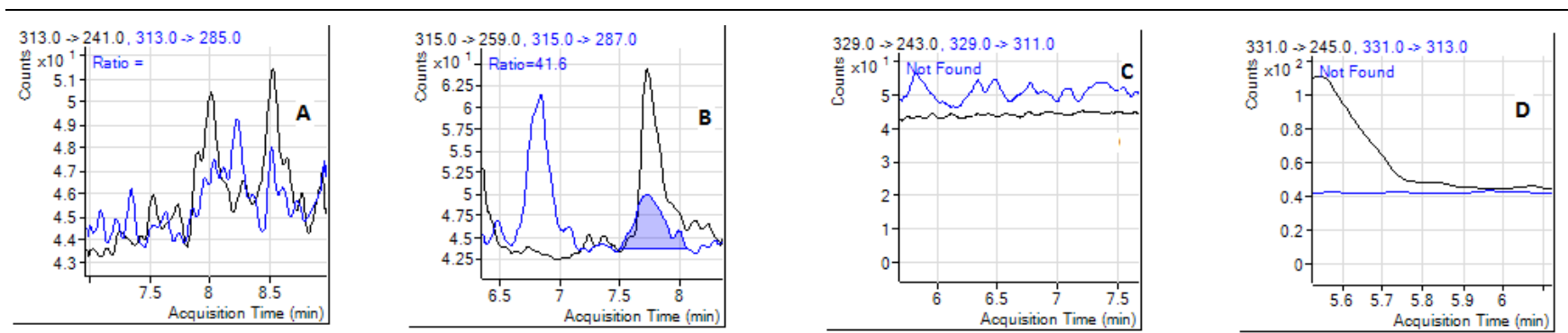

Figure 4. HPLC-MS/MS Chromatogram of M. pururiens Counts vs Acquisition time (min); (A) Resultant mass peak of $\mathrm{AFB}_{1}$ observed below the detection limit $(0.04 \mu \mathrm{g} / \mathrm{kg})$,(B) Resultant mass peak of $\mathrm{AFB}_{2}$ observed below the detection limit $(0.05$ $\mu \mathrm{g} / \mathrm{kg}$ ) (C) No resultant mass peak of $\mathrm{AFG}_{1}$ observed (D) No resultant mass peak of $\mathrm{AFG}_{2}$ observed. Mobile phase; methanol: acetonitrile $(70: 30 \mathrm{v} / \mathrm{v})$ eluent $\mathrm{A}$ and aqueous ammonium acetate $(5 \mathrm{mM})$ eluent $\mathrm{B}$. Total run time (5 to $8 \mathrm{~min})$, injection volume $(5 \mathrm{~mL})$ and flow rate $(5 \mu \mathrm{L} / \mathrm{min})$. The black line in the chromatogram is for quantifier ion and the blue line shows the qualifier ion for the MRM transition for LC-MS/MS of aflatoxins. Ratio in the chromatogram is quantifier to qualifier ion ratio for the compound (which determines confirmation of a compound).
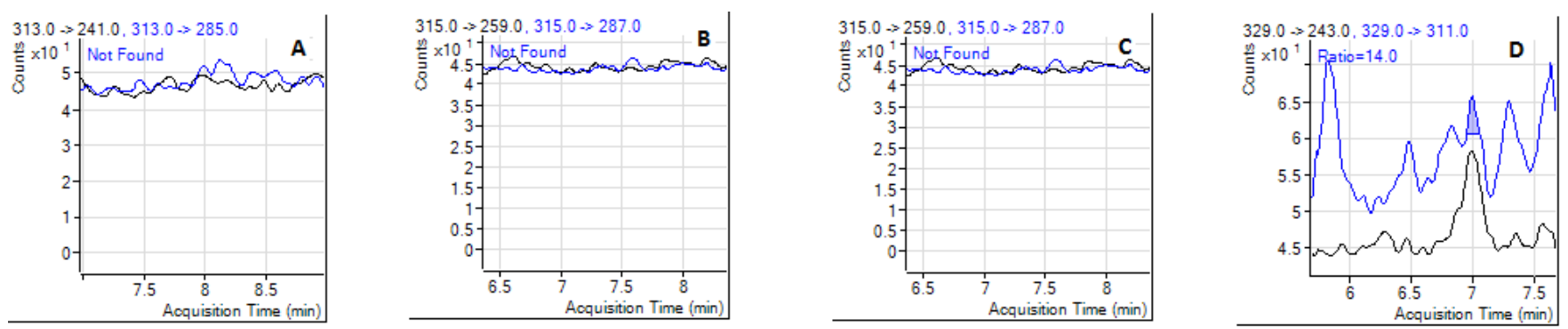

Figure 5. HPLC-MS/MS Chromatogram of $D$. denudatum. Counts vs Acquisition time (min); (A) No resultant mass peak of $\mathrm{AFB}_{1}$ observed (B) No resultant mass peak of $\mathrm{AFB}_{2}$ observed (C) No Resultant mass peak of $\mathrm{AFG}_{1}$ observed (D) Resultant mass peak of $\mathrm{AFG}_{2}$ observed below the detection limit $(0.07 \mu \mathrm{g} / \mathrm{kg})$. Mobile phase: methanol: acetonitrile $(70: 30 \mathrm{v} / \mathrm{v})$ eluent $\mathrm{A}$ and aqueous ammonium acetate $(5 \mathrm{mM})$ eluent B. Total run time $(5$ to $8 \mathrm{~min})$, injection volume $(5 \mathrm{~mL})$ and flow rate $(5$ $\mu \mathrm{L} / \mathrm{min}$ ). The black line in the chromatogram is for quantifier ion and blue line shows the qualifier ion for the MRM transition for LC-MS/MS of aflatoxins. Ratio in the chromatogram is quantifier to qualifier ion ratio for the compound, (which determines confirmation of a compound).
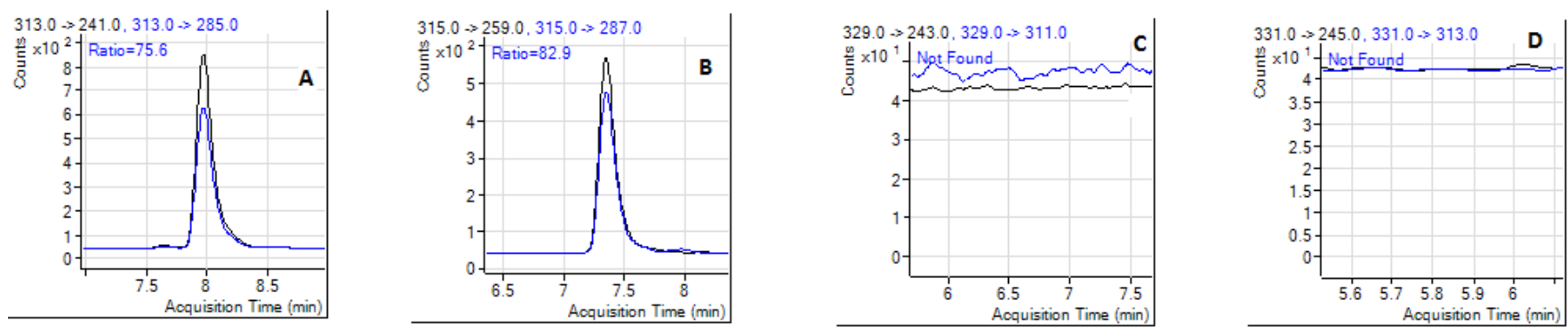

Figure 6. HPLC-MS/MS Chromatogram of $P$. oleraceae Counts $v s$ Acquisition time (min) (A) Resultant mass peak of $\mathrm{AFB}_{1}$ observed $\left(1.675 \mu \mathrm{g} / \mathrm{kg}\right.$ ) (B) Resultant mass peak of $\mathrm{AFB}_{2}$ observed $(1.335 \mu \mathrm{g} / \mathrm{kg})(\mathrm{C})$ No resultant mass peak of $\mathrm{AFG}_{1}$ observed (D) No resultant mass peak of $\mathrm{AFG}_{2}$ observed. Mobile phase: methanol: acetonitrile $(70: 30 \mathrm{v} / \mathrm{v})$ eluent $\mathrm{A}$ and aqueous ammonium acetate $(5 \mathrm{mM})$ eluent $\mathrm{B}$. Total run time ( 5 to $8 \mathrm{~min})$, injection volume $(5 \mathrm{~mL})$ and flow rate $(5 \mu \mathrm{L} / \mathrm{min})$. The black line in the chromatogram is for quantifier ion and the blue line shows the qualifier ion for the MRM transition for LC-MS/MS of aflatoxins. Ratio in the chromatogram is quantifier to qualifier ion ratio for the compound, (which determines confirmation of a compound). 
Table 4. Summary of contamination levels of aflatoxins in herbs $(\mu \mathrm{g} / \mathrm{kg})$ obtained from LC-Mass spectroscopy Abbreviations: BDL: Below detection limit; ND: Not detected.

\begin{tabular}{llllll}
\hline Name of herb & $\mathrm{AFB}_{1}$ & $\mathrm{AFB}_{2}$ & $\mathrm{AFG}_{1}$ & $\mathrm{AFG}_{2}$ & Total AF \\
\hline Mucuna pruriens & $\mathrm{BDL}(0.04)$ & $\mathrm{BDL}(0.05)$ & $\mathrm{ND}$ & $\mathrm{ND}$ & 0.09 \\
Delphinium denudatum & $\mathrm{ND}$ & $\mathrm{ND}$ & $\mathrm{ND}$ & $\mathrm{BDL}(0.07)$ & 0.07 \\
Portulaca oleraceae & 1.675 & 1.335 & $\mathrm{ND}$ & $\mathrm{ND}$ & 3.01 \\
\hline
\end{tabular}

Amongst the four AFs, $\mathrm{AFB}_{1}$ was detected as the most common contaminant. The AFs occurred in the order of $\mathrm{AFB}_{1}>\mathrm{AFB}_{2}>\mathrm{AFG}_{1}>\mathrm{AFG}_{2}$. Aspergillus flavus is a very common fungus which infects plants and produces $\mathrm{AFB}_{1}$ and $\mathrm{AFB}_{2}$. However levels of $\mathrm{AFG}_{1}$ and $\mathrm{AFG}_{2}$ are less often detected in plants because the fungus Aspergillus parasiticus does not infect plants very often (52). This may account for the high incidence and concentrations of $\mathrm{AFB}_{1}$ and $\mathrm{AFB}_{2}$ compared with $\mathrm{AFG}_{1}$ and $\mathrm{AFG}_{2}$ in the three plants investigated in this study. Rhizomes, roots, seeds and fruits have apparently higher AFs than in flowers, indicating that the herbs rich in starch and oil might be more favorable for fungal growth (53). In particular, contamination levels of some samples i.e. root of $D$. denudatum, seeds of $M$. pruriens and $P$. oleraceae were notable, as all of these have a content of fat or fatty oil, suggesting that plants and their products rich in fat or fatty acids should be carefully monitored. The plant samples should be dried as soon as possible and stored in moistureproof containers with good aeration to avert the growth of AFs, as inappropriate storage and moisture content in samples encourages augmentation of mycotoxins (54). We conclude from this study that the risk of AF contamination in medicinal herb like $M$. pruriens, D. denudatum and P. oleraceae appears low but the presence of AFs in these plants needs to be analyzed before processing to confirm the absence of mycotoxins. The consumer must be cautious while consuming these plants for medicinal purposes. The monitoring scheme described could be applied to determine the aflatoxin contamination in a large number of samples in a cost and time effective manner. The data obtained from this monitoring can be used as a basis for risk analysis of aflatoxin contamination, thereby maintaining the aflatoxin contents at the lowest possible levels.

\section{ACKNOWLEDGMENTS}

The authors gratefully acknowledge the Department of Pharmacognosy and Phytochemistry, Faculty of
Pharmacy, Jamia Hamdard, New Delhi and Council of scientific and industrial research (CSIR) Government of India for financial assistance (09/591(0106)/2011EMR-I). The authors thank Professor Basil Roufogalis for help with preparation of the manuscript.

\section{REFERENCES}

1. Bhaskar A, Vidhya V, Ramya M. Hypoglycemic effect of Mucuna pruriens seed extract on normal and streptozotocin-diabetic rats. Fitoterapia 2008 Dec; 79(7-8):539-543.

2. Siddhuraju P, Becker K. Rapid reversed-phase high performance liquid chromatographic method for the quantification of L-dopa (L-3,4dihydroxyphenylalanine), nonmethylated and methylated tetrahydroisoquinoline compounds from Mucuna beans. Food Chem 2001 Feb; 72(3):389-394.

3. Carsky RJ, Tarawali SA, Becker M, Chikoye D, Tian G, Sanginga N, et al. Mucuna- Herbaceous cover legume with potential for multiple uses. Resource \& Crop Management Research Monograph 1998; $25: 54$.

4. Spencer JPE, Jenner P, Halliwell B. Superoxidedependent GSH depletion by L-DOPA and dopamine. Relevance to Parkinson's disease. Neuro Report 1995 Jul; 6(11):1480-1484.

5. Qudsia N, Jafri MA. Unani drug, Jadwar (Delphinium denudatum Wall.) - A review. IJTK 2006 Oct; 5(4):463-467.

6. Zafar S, Aftab MA, Siddiqui TA. Jadwar (Delphinium denudatum Wall.) Roots - A Boon in Unani Medicine. Hamdard Med 2003; 6(2):9-14.

7. Rahman SZ, Khan RA, Kumar A. Experimental study of the morphine de-addiction properties of Delphinium denudatum Wall. BMC Complem Altern Med 2002 May; 2(6).

8. Rahman SZ, Khan RA, Kumar A. Pharmacological study of Delphinium denudatum Wall in morphine deaddiction. J Neurochem 2007 Aug; 102 (Suppl.1):142143.

9. Ahmad G, Yousuf A, Khan KM, Tajuddin NA. The anti stress activity of a gem containing Unani formulation against diverse stress. J Ethnopharmacol 2004 Feb; 90(2-3):367-74.

10. Singh N, Chopra KL. Diterpine alkaloid isolation and study of two new alkaloids. J Pharma and Pharmaceutic 1962; 14:288-293. 
11. Oh KB, Chang IM, Hwang KJ, Mar W. Detection of antifungal activity in Portulaca oleracea by a singlecell bioassay system. Phytother Res 2000 Dec; 14(5):329-332.

12. Islam MW, Zakaria MNM, Radhakrishnan R, Habibullah M, Chan K. Evaluation of analgesic activity of the aerial parts of Portulaca oleracea v. sativa and its comparison with other two related species. J Pharm Pharmacol 1998; 50(Suppl):226.

13. Chan K, Islam MW, Kamil M, Radhakrishnan R, Zakaria MN, Habibullah M, Attas A, et al. The analgesic and anti-inflammatory effects of Portulaca oleracea L. subsp. Sativa (Haw.) Celak. J Ethnopharmacol 2000 Dec; 73(3):445-51.

14. Radhakrishnan $\mathrm{R}$, Zakaria MN, Islam MW, Chen HB, Kamil M, Chan K, Al-Attas A, et al. Neuropharmacological actions of Portulaca oleraceae L v. sativa (Hawk). J Ethnopharmacol 2001 Jul; 76(2):171-176.

15. Ullah M O, Haque M, Urmi K F, Zulfiker A H, Anita E S , Begum M, Hamid K. Anti-bacterial activity and brine shrimp lethality bioassay of methanolic extracts of fourteen different edible vegetables from Bangladesh. Asian Pac J Trop Biomed 2013 Jan; 3(1):1-7.

16. Li HY, Wang XS. A study on extracting method of polysaccharide from Portulaca oleracea. J Branch Campus First Military Med 2005; 2:186-187.

17. Mohammad TB, Mohammad HB, Farhad M. Antitussive effect of Portulaca oleracea $\mathrm{L}$ in guinea pigs. Iran J Pharmaceut Res 2004;3: 187-190.

18. Meng FB, Wu RG. Appraisal on medicinal values of Portulaca oleracea L. Forest Investig Des 2008; 1:7778.

19. Eaton DL.; Groopman JD.;The Toxicology of aflatoxins, Human health, veterinary and agricultural significance. Academic Press, New York, 1994.

20. Hussein HS, Brasel JM. Toxicity, metabolism and impact of mycotoxins on humans and animals. J Toxicol 2001; 167:101-109.

21. Joshua H. Determination of aflatoxins by reversedphase high-performance liquid chromatography with post-column in-line photochemical derivatization and fluorescence detection. J Chromatogr A 1993 Nov; 654 (2):247-254.

22. Abeywickrama E, Bean GA. Toxigenic Aspergillus flavus and aflatoxins in Sri Lankan medicinal plant material. Mycopathologia 1991 Mar; 113(3):187-190.

23. Ip SP, Che CT. Determination of aflatoxins in Chinese medicinal herbs by high-performance liquid chromatography using immunoaffinity column cleanup Improvement of recovery. J Chromatogr A 2006 Dec; 1135 (2):241-244.

24. Escobar A, Regueiro OS. Determination of aflatoxin B1 in food and feedstuffs in Cuba using an immunoenzymatic reagent kit (Aflacen). J Food Prot 2002; 65:219-221.
25. Mphande FA, Siame BA, Taylor JE. Fungi, aflatoxins and cyclopiazonic acid associated with peanut retailing in Botswana. J Food Prot 2004 Jan; 67(1):96-102.

26. Urraca JL, Marazuela MC, Moreno-Bondi MC. Analysis for zearalenone and a-zearalenol in cereals and swine feed using accerelated solvent extraction and liquid chromatography with fluorescence detection. Anal Chim Acta 2004 Oct; 524 (1-2):175-183.

27. Juan C, Zinedine A, Molto JC, Idrissi L, Manes J. Aflatoxins levels in dried fruits and nuts from RabatSale area, Morocco. Food Control 2008 Sept; 19 (9):849-853.

28. Gilbert J, Anklam E. Validation of analytical methods for determining mycotoxins in foodstuffs. Trends Anal Chem 2002 Jun; 21(6-7): 468-486.

29. Kerstin H, Charity M. Aflatoxin control and prevention strategies in key crops of Sub-Saharan Africa. Afr J Microbiol Res 2011; 5(5):459-466.

30. Reddy KRN, Salleh B. Co-Occurrence of Moulds and Mycotoxins in Maize Grains Used for Animal Feeds in Malaysia. J Anim Vet Adv 2011 Mar; 10(5):668-673.

31. Roy AK, Sinha KK, Chourasia HK. Aflatoxin contamination of some common drug plants. Appl Environ Microbiol 1988 Mar; 54(3):842-843.

32. Han Z, Zheng Y, Luan L, Cai Z, Ren Y, Wu Y, et al. An ultra-high-performance liquid chromatographytandem mass spectrometry method for simultaneous determination of aflatoxins B1, B2, G1, G2, M1 and M2 in traditional Chinese medicines. Anal Chim Acta 2010 Apr; 664(2):165-171.

33. Sugita-Konishi Y, Sato T, Saito S, Nakajima M, Tabata S, Tanaka T, Norizuki H, Itoh Y, Kai S, Sugiyama K, Kamata Y, Yoshiike N, Kumagai $S$ et al. Exposure to aflatoxins in Japan: risk assessment for aflatoxin B1. Food Addit Contam Part A Chem Anal Control Expo Risk Assess 2010; 27(3):365-72.

34. Ubwa ST, Asemave K, Igbum GO. Preliminary screening of aflatoxin level in maizen (Zea mays L.) in some selected markets in Benue State, Nigeria. AJPAC 2012 Dec; 6(14):159-163.

35. The Natural Health Products Directorate (NHPD), Quality of Natural Health Products Guide". Version 3.0- 17 August, 2012: http://www.hc-sc.gc.ca/dhp$\mathrm{mps} /$ consultation/natur/consult_quality-qualit eng.php.

36. CodexAli mentarius Commission. Joint FAO/WHO food standards programme, codex committee on food additives and contaminants. Thirty-third session (2001) CODEX, Hague, Netherlands.

37. Safety evaluation of certain food additives and contaminants. WHO Food Additive Series: 59 (2008).http://www.who.int/foodsafety/chem/jecfa/pub lications/monographs/en/index.html.

38. European Economic Community Council. Commission regulation (EC) No.1525/98. Official Journal of European Communities 1998; 201:43-46. 
39. Commission Regulation (EC) No $472 / 2002$ of 12 March 2002 amending regulation (EC) No 466/2001 setting maximum levels for certain contaminants in foodstuffs. Official Journal of the European Communities L75/18, Luxembourg.

40. Alexander RF, Baur MC. Note on a two TLC procedure for determining Aflatoxin in maize. Cereal Chem 1977 May; 54:699-704.

41. Younis YMH, Malik MK. TLC and HPLC assay of aflatoxin contamination in Sudanese peanuts and peanut products. Kuwait J Sci Eng 2003; 30 (1):79-93.

42. Waltking AE, Wilson D. Liquid chromatographic analysis of aflatoxin using post-column photochemical derivatization: collaborative study. J AOAC Int 2006 May; 89(3):678-692.

43. Sobolev VS. Simple, rapid, and inexpensive cleanup method for quantitation of aflatoxins in important agricultural products by HPLC. J Agric Food Chem 2007 Mar; 55(6):2136-2141.

44. Kamkar A. A study on the occurrence of aflatoxin M1 in raw milk produced in Sarab city of Iran. Food Control 2005 Sept; 16(7):593-599.

45. Alborzi S, Pourabbas B, Rashidi M, Astaneh B. Aflatoxin M1 contamination in pasteurized milk in Shiraz (south of Iran). Food Control 2006 Jul; 17(7):582-584.

46. Heshmati A, Milani JM. Contamination of UHT milk by aflatoxin M1 in Iran. Food Control 2010 Jan; 21(1):19-22.

47. Maragos CM, Appell M, Lippolis V, Visconti A, Catucci L, Pascale M. Use of cyclodextrins as modifiers of fluorescence in the detection of mycotoxins. Food Addit Contam 2008; 25(2):164-171.
48. Somashekar D, Rati ER, Chandrashekar A. PCRrestriction fragment length analysis of aflR gene for differentiation and detection of Aspergillus flavus and Aspergillus parasiticus in maize. Int J Food Microbiol 2004 May; 93(1):101-107.

49. Scherm B, Palomba M, Serra D, Marcello A, Migheli Q. Detection of transcripts of the aflatoxin genes aflD, $a f l O$, and aflP by reverse transcription-polymerase chain reaction allows differentiation of aflatoxinproducing and non-producing isolates of Aspergillus flavus and Aspergillus parasiticus. Int J Food Microbiol $2005 \mathrm{Feb}$; 98(2):201-210.

50. Shim WB, Kim K, Ofori JA, Chung YC, Chung DH. Occurrence of aflatoxins in herbal medicine distributed in South Korea. J Food Protect 2012; 75(11):1991-99.

51. Ali N, Hashim NH, Saad B, Safan K, Nakajima M, Yoshizawa $\mathrm{T}$, et al. Evaluation of a method to determine the natural occurrence of aflatoxins in commercial traditional herbal medicines from Malaysia and Indonesia. Food Chem Toxicol 2005 Dec; 43(43): 1763-1772.

52. Dorner JW, Richard JC, Diener UL. The relationship of Aspergillus flavus and A. parasiticus with reference to production of aflatoxins and cyclopiasonic acid. Mycopathologia 1984 Aug; 87(1-2):13-15.

53. Romagnoli B, Menna V, Gruppioni N, Bergamini C. Aflatoxins in spices, aromatic herbs, herb-teas and medicinal plants marketed in Italy Food control 2007 June; 18(6):697-701.

54. Schroeder HW. Factors influencing the development of aflatoxins in some field crops. J Stored Prod Res 1969 Nov; 5(3):187-192. 